\title{
CRISE ECONÔMICA, PROVISÃO HABITACIONAL E A (DES) CONSTRUÇÃO DO DIREITO À CIDADE NO PERÍODO BNH
}

\section{ECONOMIC CRISIS, HOUSING PROVISION AND (DE) CONSTRUCTION OF THE RIGHT TO THE CITY IN THE BNH PERIOD}

Simone Silva Costa ${ }^{1}$

\section{Resumo}

Este estudo busca compreender o debate sobre a produção capitalista da habitação social. Especificamente, sobre a cooptação da provisão habitacional pelo Banco Nacional de Habitação (BNH) pelos governos militares. Defendemos a tese de que a política praticada, naquele período, beneficiava os interesses da elite nacional e do grande capital, instigando assim a luta de classes pelo direito à cidade. Mostraremos que a crise econômica e social dos anos de 1960, permitiu a formação das condições materiais objetivas para o golpe militar em 1964, bem como o uso da política habitacional formulada no âmbito do Banco Nacional de Habitação (BNH) aos interesses privados em detrimento da construção de cidades justas. Em seguida, faremos uma breve revisão de literatura sobre a questão da crise econômica na visão de Rosa Luxemburgo e procuraremos analisar, numa perspectiva histórica, a (des) construção do direito à cidade, no período BNH, destacando a participação do Estado neste processo, já que o mesmo atende as necessidades reprodutivas do sistema capitalista, no sentido de minimizar as crises do capital

Palavras-Chave: Provisão habitacional. Habitação Social. Banco Nacional de Habitação. Crise econômica. Direito à cidade.

\begin{abstract}
This study seeks to understand the debate on the capitalist production of social housing. Specifically, on the cooptation of housing provision by the National Housing Bank (BNH) by military governments. We defend the thesis that the policies practiced by the government, at that time, benefited the interests of the national elite and the great capital, thus instigating the class struggle for the right to the city. We will show that the economic and social crisis of the 1960s allowed the formation of objective material conditions for the military coup in 1964, as well as the use of housing policy formulated within the scope of the National Housing Bank (BNH) to private interests over the Construction of fair cities. Then we will briefly review the literature on the issue of the economic crisis in Rosa Luxemburg's view and attempt to analyze, in a historical perspective, the (de) construction of the right to the city in the BNH period, highlighting the participation of the State in this process, since It meets the reproductive needs of the capitalist system to minimize crises of capital.
\end{abstract}

Keywords: Housing provision. Social habitation. National Bank of Housing. Economic crisis. Right to the city.

\footnotetext{
${ }^{1}$ Doutora pelo Curso de Arquitetura e Urbanismo da Universidade Federal do Rio Grande do Norte. Email: mone_win@hotmail.com
} 


\section{INTRODUÇÃO}

Este estudo busca compreender o debate sobre a produção capitalista da habitação social. Especificamente, a provisão habitacional da moradia pelo Banco Nacional de Habitação (BNH), a qual contribuiu para a cooptação da política habitacional pelos governos militares para silenciar os movimentos sociais em curso contra o regime, bem como minimizar os efeitos da crise econômica dos anos de 1960. O resultado desta atitude foi o acirramento da luta de classes pelo direito à cidade. A definição de classe social fornecida por Lênin (1977) evidencia a relação direta entre a existência de classes e a luta entre elas.

Chamam-se classes a grandes grupos de homens que se diferenciam pelo seu lugar no sistema historicamente determinado de produção social, pela sua relação (na maioria dos casos confirmada e precisada nas leis) com os meios de produção, pelo seu papel na organização social do trabalho e, por conseguinte, pelos meios de obtenção e pelo volume da parte da riqueza social de que dispõem. As classes são grupos de homens em que uns podem apropriar-se do trabalho dos outros graças à diferença do lugar que ocupam num sistema da economia social (LÊNIN, 1977, p. 13).

Numa sociedade dividida em classes sociais, a luta pelo direito à cidade envolve pensar como a cidade é produzida de maneira desigual. O que se almeja não é apenas o direito à terra, mas o direito à cidadania, à vida na cidade. No entanto, o modelo econômico adotado no Brasil a partir dos anos de 1930 se desenvolveu sob os moldes do capital produtivo e mercantil, ou seja, o modelo privilegiava os interesses capitalistas em detrimento dos direitos e do bem-estar da população por boa moradia. CANO (2010, p. 2), define o capital mercantil como sendo as formas Comercial e Usuária, as quais tem suas origens no período anterior à Acumulação Primitiva de Capital. "Antecede, portanto a etapa do capitalismo originário, quando surgiria a forma Produtiva, ou a do Capital Industrial e restringe-se à órbita da circulação".

Já o direito à cidade, segundo Trindade (2012, p. 140), "é uma plataforma política a ser construída e conquistada pelas lutas populares contra a lógica capitalista de produção da cidade, que mercantiliza o espaço urbano e o transforma em uma engrenagem a serviço do capital". No conceito de Lefebvre (2001, p. 4) a cidade, enquanto centro da vida social e política deve ser desfrutada por todas as classes sociais, pois além da sua capacidade de acumular riquezas e valorizar o capital, reúne também os conhecimentos, as técnicas e as obras (obras de arte, monumentos). Para este autor, a cidade é uma obra que possui valor de uso, mas a sociedade movida pelo capital produtivo e mercantil, a transformou num valor de troca, ou seja, numa mercadoria. 
No momento em que nossa sociedade caminhava para sua primeira crise como economia industrial capitalista madura, houve uma necessidade política de efetivar o golpe militar. A partir de 1964, com a supressão dos direitos políticos, o povo brasileiro sofreu uma violação da sua cidadania e no seu direito de participar da "cidade". Os militares, a classe empresarial e a classe média mais conservadora não aceitavam a ideia de Goulart, um político comprometido com as bases sindicais, abraçar a liderança do Poder Executivo. A situação econômica corrompia ainda mais a situação política (BRUM, 1996).

Durante os governos ditatoriais foram editados 17 atos institucionais. $\mathrm{O}$ ato institucional número 5 (Al-5), instituído em 1968, foi o mais violento, pois, suspendeu o princípio do habeas corpus e instituiu, de forma clara e objetiva, a tortura e a violência física contra os opositores do regime. Ou seja, mergulhou o país numa profunda repressão política e violação dos direitos fundamentais (OLIVEIRA, 2012).

Para alcançar os objetivos propostos neste trabalho, no tópico 1, refletiremos sobre a natureza das crises econômicas no pensamento de Rosa Luxemburgo, a fim de compreendermos porque motivo a política de habitação costuma ser cooptada nas fases recessivas do ciclo econômico. Com efeito, as crises do capital são o resultado da operação das contradições inerentes ao modo de produção capitalista. Elas não decorrem de eventos que acontecem fora do sistema econômico, mas emergem em virtude do seu próprio desenvolvimento (HARVEY, 2005).

No tópico 2, resgataremos a trajetória da política de habitação social e de como ela acirrou a luta de classes, especificamente a luta pelo direito à cidade. Neste tópico, mostraremos que a crise econômica e social dos anos de 1960, permitiu a formação das condições materiais objetivas para o golpe militar em 1964 e a cooptação da política habitacional formulada no âmbito do Banco Nacional de Habitação (BNH) aos interesses do capital.

Nas considerações finais, argumentações que a produção capitalista da habitação popular no período BNH, ao ser utilizada como respostas às crises econômicas e políticas, naquele momento histórico, além de desenvolver uma enorme desigualdade sócio espacial, acirrou o crescimento da cidade ilegal, ou seja, "da "periferização" das grandes metrópoles. Este fenômeno foi fruto, também, do aumento populacional nos municípios da franja metropolitana, reproduzindo e expandindo a cidade nas formas de favelas e cortiços (MARICATO, 1996). 


\section{A CRISE ECONÔMICA NA VISÃO DE ROSA LUXEMBURGO}

Em algumas passagens de O Capital, MARX (1988) nos esclarece a importância do capital mercantil para a acumulação do sistema. Era sua intenção conhecer o processo de valorização do capital, o qual vai de encontro ao conceito de direito à cidade, inclusive ao processo de construção de cidades justas.

Conforme definido por Karl Marx apud Rubin (1980), no capitalismo, a busca pela valorização do capital faz com que tudo se transforme em mercadoria, com a moradia não é diferente. Para explicar esta transformação, Marx aborda a questão do fetichismo da mercadoria. Este autor observou que, no capitalismo, a relação entre pessoas aparece como uma relação entre as coisas. Há na mercadoria uma certa magia que aceita a aparência dos fenômenos (a troca das mercadorias e seus preços de mercados) como essência dos fenômenos econômicos.

Portanto, quando a cidade é transformada em mercadoria, a população terá muitas dificuldades de acessá-la. Os capitalistas, em especial o proprietário imobiliário, ao contrário, atuará no sentido de evitar as crises, bem como buscará auferir lucros extraordinários por meio da construção de grandes empreendimentos, notadamente nos períodos de expansão do ciclo econômico. Neste contexto, eles não aparecem como pessoas com um lugar determinado no espaço urbano, mas como proprietários e possuidores de coisas, ou seja, de mercadorias, buscando a valorização do seu capital. Por outro lado, quando o ciclo econômico entra em declínio é possível que, dentre outros fatores, a política habitacional seja cooptada para atender às necessidades do capital (HARVEY, 2005).

Talvez seja útil levar em conta o último elemento e considerar como se pode elaborar um novo nível de demanda efetiva, capaz de aumentar a capacidade de absorção de produtos (...). A demanda da classe trabalhadora por boa moradia talvez seja cooptada por um programa pública de habitação, que serve para estabilizar a economia e para aumentar a demanda por materiais de construção de determinado tipo (HARVEY, 2005, p. 47, 48).

No marxismo, a crise do capital sempre se constituiu no momento da verdade para a prática revolucionária, aquela que abriria a contagem para o fim do sistema. No entanto, logo se compreendeu que as crises são a própria forma do capitalismo resolver suas contradições. Dentre as vertentes existentes na literatura econômica marxista para explicar a natureza das crises, temos: a teoria do subconsumo de Rosa Luxemburgo.

Em 1913, Rosa Luxemburgo, expoente da nova esquerda, no seu livro "A acumulação do capital", discutiu o tema do imperialismo a fim de explicar o problema da reprodução ampliada 
do capital. Essa reprodução, segundo a referida autora, pressupõe determinado nível de produtividade do trabalho. Assim, o consumo de uma sociedade dependerá do que foi produzido e da forma como se produz. O foco de sua investigação recai sobre as dificuldades que surgem na esfera da circulação de mercadorias. Ou seja, no problema de realização da mais-valia (LUXEMBURGO, 1984).

No capitalismo, o processo de produção, inclusive da habitação, envolve decisões do que e do quanto produzir, as quais são realizadas no mercado através do mecanismo de sistema de preços. O capitalista só produz habitações porque ele vê a possibilidade de multiplicar os seus investimentos. Ele não se preocupa em produzir valores de usos, mas em produzir maisvalia por meio da exploração do trabalhador no setor produtivo.

O capitalista não está interessado no valor de uso que produziu. O que Ihe importa é que esta mercadoria que produziu é valor de uso para outra pessoa, e que esta mercadoria possui valor (incluindo a mais-valia). Assim, embora the interesse apenas o valor, o capitalista é forçado a produzir um valor de uso específico, pois só através desse é que ele pode obter o valor. E, como seu objetivo é a apropriação de uma mais-valia, ele só o conseguirá quando a mercadoria produzida for trocada por dinheiro, no mercado (CARCANHOLO, 2007, p. 1).

A crise, neste contexto, se apresenta quando o processo de acumulação é descontínuo. Ou seja, quando a realização da mais-valia é interrompida no mercado. Para Luxemburgo, a realização da mais-valia não ocorre por parte dos trabalhadores assalariados ou pela classe capitalista, mas por um grupo de compradores que se situam fora da sociedade capitalista e que ela denomina de mercado externo. Assim, quando a produção capitalista, fornecesse os meios de consumo acima das necessidades dos operários e dos capitalistas, era preciso exportar o excedente produtivo para países não capitalistas. A insuficiência de demanda não permitiria a realização da parcela do valor que corresponde à mais-valia e, portanto, os capitalistas não poderiam acumular (LUXEMBURGO, 1984).

O fato é que a pobreza e a restrição de consumo das massas nos países capitalistas, dado o elevado desemprego e os baixos salários, em detrimento da produção massiva, na visão de Luxemburgo, colocava um limite para a reprodução do capitalismo. Neste contexto, o imperialismo constitui a luta entre os países capitalistas desenvolvidos pelas condições restantes de acumulação ainda presentes no mundo não capitalista.

Porém, à medida que a expansão colonial possibilitava a realização da mais-valia nas sociedades pré-capitalistas ela destruía, ao mesmo tempo, os sistemas sociais que são a condição essencial para o prosseguimento da acumulação nos países centrais do capitalismo, por meio da exportação de seu modo de produção específico para as regiões não capitalistas. 
Por fim, com a expansão global do modo de produção capitalista, não haveria uma demanda externa suficiente para o consumo da mais-valia e, por isso, a acumulação capitalista estaria no seu limite final. Essa contradição é inevitável sob o capitalismo e a fase imperialista do capital representaria o desfecho de todas as condições que asseguram a reprodução do capital. Logo, o resultado das crises econômicas, tão comuns no capitalismo, seriam as responsáveis pelo fim do próprio sistema. A solução para as crises poderia ser resolvida pela aplicação dos princípios do socialismo.

O capitalismo é a primeira forma econômica capaz de propagar-se vigorosamente: é uma forma que tende a estender-se por todo o globo terrestre e a eliminar todas as demais formas econômicas, não tolerando nenhuma outra a seu lado. Mas é também a primeira que não pode existir só, sem outras formas econômicas de que alimentar-se; que, tendendo a impor-se como forma universal, sucumbe por sua própria incapacidade intrínseca de existir como força de produção universal. O capitalismo é, em si, uma contradição histórica viva; seu movimento de acumulação expressa a contínua resolução e, simultaneamente, a potencialização dessa contradição. A certa altura do desenvolvimento essa contradição só poderá ser resolvida pela aplicação dos princípios do socialismo - daquela forma de economia que por sua natureza é ao mesmo tempo um sistema internacional e harmônico, por não visar à acumulação, mas à satisfação das necessidades vitais da própria humanidade trabalhadora, por meio do desenvolvimento de todas as forças produtivas do planeta. (LUXEMBURGO, 1984, p.98)

Na visão de Rosa Luxemburgo (1984), além da conversão violenta da terra (atualmente moradia e terra urbana) e da força de trabalho em mercadorias, o estabelecimento do capitalismo como sistema produtivo a partir da Revolução Industrial, no século XVIII, promoveu a criação do mercado mundial e uma "história universal". Portanto, baseando-se nessa visão, entendemos que estes dois elementos interligados modificaram de forma radical as condições de vida e de luta social pelo urbano, no sentido de romper potencialmente todos os limites à mercantilização da vida e da cidade.

No início do século XX, acelerou-se tanto a concorrência entre os capitais (impelindo-os a busca de novos mercados no exterior) quanto a violência organizada pelo Estado (militarismo, nos termos de Rosa Luxemburgo). Com isso, o capitalismo, na sua eterna luta contra as "economias naturais", recorre ao emprego de mecanismos de exploração herdados de outros modos de produção que, uma vez conexos a uma lógica mercantil, tendem a ser intensificados e, finalmente, integrados à sua dinâmica. Esse processo exige a transformação radical das estruturas do cotidiano das sociedades que invade. A busca por estas transformações resulta, portanto, nas crises econômicas do capital. 
Compreendendo o conceito de crise econômica na visão de Luxemburgo, no próximo tópico faremos uma reflexão sobre a cooptação da política de habitação social a partir de 1964, e das medidas tomadas pelo governo para minimizar as lutas de classes, bem como ao combate do declínio da renda, e do produto.

\section{A CRISE ECONÔMICA BRASILEIRA E A COOPTAÇÃO DA PROVISÃO HABITACIONAL PELO CAPITAL NA DÉCADA DE 1960}

Conforme vimos no tópico anterior, o capitalismo é marcado por constantes crises econômicas. Para Luxemburgo, as crises são resultado da falta de demanda, ou seja, trata-se de uma crise de subconsumo. Portanto é preciso que a produção de mercadorias encontre mercado para que o sistema não entre em colapso.

De acordo com AZEVEDO e ANDRADE (1982), a partir da década de 1930, a questão da produção habitacional entrou para a agenda governamental brasileira com o reconhecimento da problemática urbana. No entanto, não era objetivo dos governos tecnocráticos produzir moradia digna e bem localizada, mas fortalecer e legitimar o poder do Estado. Ainda na década de 1920, especificamente em 1923, as Caixas de Aposentadoria e Pensões (CAPs) foram autorizadas a financiar a construção de moradias, mas atendiam apenas a algumas categorias profissionais, tais como: industriários, comerciários e bancários. Somente com a criação da Fundação da Casa Popular (FCP), em 1946, é que o governo atuaria na provisão habitacional voltada exclusivamente para a construção de casas populares às classes de menor poder aquisitivo.

A FPC, surgiu como uma resposta do Estado à forte crise nacional de habitação, que atingia, principalmente, a cidade do Rio de Janeiro, num momento de intensa politização da população acerca da questão urbana. Esta questão estava sendo debatida nos discursos voltados para as favelas e mocambos. Seu desenho era bastante ambicioso, pois além da provisão de moradias, previa também diversas ações voltadas à formulação e execução de uma efetiva política urbana, do financiamento de "obras urbanísticas de abastecimento d'água, esgotos, suprimento de energia elétrica, assistência social e outras que visam à melhoria das condições de vida e bem-estar das classes trabalhadoras" (TROMPOWSKY, 2004, p.4).

Ao longo das décadas, notamos a ausência de mecanismo que assegurassem um maior monitoramento do governo federal no sentido de fazer com que as políticas de governo, especificamente da área habitacional, se transformassem em políticas de Estado. O fracasso das 
políticas foi afetado por diversas conjunturas econômicas recessivas, bem como pelas diferentes capacidades institucionais disponíveis no plano local - recursos humanos, capacidade de gestão e articulação entre diversos serviços e políticas, infraestrutura disponível.

Diante do quadro urbano problemático, em 1963, o presidente João Goulart apresentou uma declaração ao Congresso Nacional abordando a necessidade da realização de uma reforma urbana. Contudo, após o golpe de 1964, os movimentos sociais perderam força e o seu âmbito de ação foi bastante enfraquecido. Ao mesmo tempo, persistiam as desigualdades na cidade como consequência das políticas públicas injustas (BRUM, 1996).

Os eventos ocorridos no início da década de 1960 provocaram mudanças significativas na sociedade brasileira. Do ponto de vista político, o sistema democrático foi substituído pelo autoritarismo. No plano econômico, particularmente após 1963, o país se viu envolvido numa grave crise econômica, cujo resultado foi o declínio do produto interno bruto (PIB) e da renda.

Toda crise se caracteriza por um declínio de produção econômica e do nível de emprego e dos salários, por uma crescente insatisfação e descontentamento em relação ao "status quo", pela mobilização e dinamismo da consciência social dos diversos segmentos que compõem a sociedade, pelo aguçamento do debate nacional em torno das proposições em busca de saídas, com vistas a superação da situação crítica (BRUM, 1996, p. 122).

Conforme FAGNANI (2005), em virtude da crise, no período de 1961 a 1964, esgotaramse as possibilidades de crescimento da economia brasileira. O país entrou numa fase de recessão e estagnação. O desemprego e os baixos salários contribuíram para o aumento da pobreza. Sem emprego e sem renda agregados, o processo de favelização e da moradia precária tornava-se cada vez mais intenso. No auge da crise, procurando evitar o progresso dos setores populares cada vez mais apoiados pelo governo de João Goulart, os militares tomaram o poder neutralizando as forças reformistas. Com a neutralização das lutas lideradas pelo setor popular, fecharam-se os canais formais de manifestação e o diálogo entre Estado e sociedade, inclusive eliminando as possibilidades de realização da Reforma Urbana, já que esta era uma proposta do governo que foi deposto.

Neste cenário, procurando paralisar os movimentos sociais em busca do direito à cidade, o Estado adotou políticas públicas repressivas e anticíclicas, as quais beneficiavam de forma direta as classes médias e altas em detrimento do segmento popular. Segundo AZEVEDO e ANDRADE (1982), procurando aprofundar os laços entre economia brasileira e o capital internacional, na expectativa de projetar o Brasil como um país integrante do primeiro mundo, o governo ditatorial realizou diversas reformas estruturais, inclusive no seu sistema financeiro. 0 
resultado foi a aprovação de três documentos para estabelecer base legal do sistema, sendo eles:

I. A Reforma Bancária (Lei № 4595 de 31/12/1964);

II. A Reforma Habitacional, criando o Sistema Financeiro de Habitação - SFH - (Lei № 4380 de 21/08/1964);

III. A Reforma do Sistema Financeiro e do Mercado de Capitais (Lei № 4728, de 14/07/1965).

A partir destas Reformas, o Estado utilizou a política habitacional, ou melhor o Banco Nacional de Habitação (BNH), Lei 4.320/64, com o intuito de alavancar o crescimento econômico, bem como controlar as classes trabalhadoras, neutralizando os movimentos urbanos que ocorriam no país. A cooptação da política habitacional, naquele período de elevada instabilidade social se justificava na medida em que, "ser proprietário do seu próprio "chão" significava a fixação na cidade, a proteção contra a crise. Já para os desempregados era "a certeza de um teto enquanto se buscava trabalho" (BLAY, 1985, p. 81). De fato, na medida em que o governo transformava trabalhadores em proprietários de suas moradias, houve uma redução no impacto negativo do novo regime, bem como na resistência com a supressão dos direitos políticos e liberdades civis (NEVES, 2012, p. 112).

Por outro lado, no que diz respeito a saída da crise por meio da realização da mais-valia, - Estado se aliou ao capital mercantil e começou a praticar atos que violentavam o direito à cidade. Como exemplo, podemos citar a prática de remoção de favelas pelo governo. De acordo com o portal de notícias da $\mathrm{Globo}^{2}$, na década de 1960, havia uma elevada demanda por habitação social, principalmente, no Rio de Janeiro. Em 1965, cerca de 365 mil pessoas moravam em favelas nesta cidade. Hoje este número chega a 1,4 milhão. A remoção de famílias pelo Estado e a construção de moradias pelo capital produtivo estavam entre as principais manchetes dos jornais da cidade.

A ocupação da Vila Progresso, uma das comunidades que fazem parte do território da Vila Kennedy (RJ), se iniciou por volta de 1941, quando a área ainda era um sítio cujo proprietário parcelou o terreno vendendo os lotes para os moradores da região à época. Entretanto, como as famílias não pagaram os impostos ao Instituto Nacional de Colonização e Reforma Agrária (INCRA), o terreno passou a ser de propriedade da União.

\footnotetext{
2 Disponível em: <http://g1.globo.com/rio-de-janeiro/rio-450-anos/noticia/2015/03/foi-noticia-ha-50anos-rio-tinha-crise-da-falta-dagua-e-criminalidade-crescia.html>. Acesso em 08.10.2015.
} 
Em 1964, a Vila Kennedy (RJ) foi ocupada por famílias removidas pelo governo municipal. Em seu lugar, surgiu então um novo "conjunto habitacional, no bairro de Bangu, na Avenida Brasil, com 5069 unidades"3. Foram removidas para este bairro famílias que viviam em diversas outras partes da cidade como o morro do Pasmado em Botafogo e a favela do Esqueleto (RJTV, (2015, online).

Os moradores beneficiados pela referida política foram transferidos para um conjunto habitacional de casinhas idênticas e ainda em construção, distante da infraestrutura necessária ao seu bem-estar habitacional e social. Tratava-se da construção do urbano pelo capital produtivo e pelo Estado, determinado pela expansão das favelas e loteamentos informais, bem como da reprodução de condições sub-humanas de vivência e de insalubridade. O objetivo do capital era duplo: valorizar a mais-valia no âmbito da circulação e expulsar a classe trabalhadora para longe das áreas centrais.

Por outro lado, em 1967, contando com os recursos do Fundo de Garantia por Tempo de Serviço (FGTS), a produção capitalista do espaço promovido pelo modelo BNH ganhou maior dinamismo. Como os recursos eram provenientes do trabalho, era de se esperar que a população empregada fosse a mais beneficiada com os recursos, ou seja, por meio da construção de casas popular. Contrariamente, tais recursos estavam sendo investidos no setor urbano, fica claro que o trabalhador, por meio desta poupança compulsória, contribuía para o processo de socialização contraditória das forças produtivas e das relações de produção.

O BNH possuía uma gestão centralizada no governo federal e dispensava qualquer participação popular nas decisões de como enfrentar os problemas habitacionais e urbanos. A edificações das moradias eram feitas em grande escala, de forma a contribuir para expansão da cidade periférica. Todos os conjuntos habitacionais tinham características em comum: habitações simples voltadas para pessoas de baixa renda ou da classe média e localizadas em sítios isolados da cidade, o que dificultava muito a locomoção e as condições de vida da classe trabalhadora (AZEVEDO e ANDRADE, 1982).

O Banco atuou basicamente por meio das Companhias de Habitação (COHABs), a qual atendia a população até 5 salários mínimos, e dos Institutos de Orientação às Cooperativas Habitacionais (INOCOOPs) que atendiam a população que ganhava entre 6 a 12 salários mínimos, por meio de poupanças voluntárias e compulsórias. Estas poupanças, por sua vez, eram utilizadas como recursos para o financiamento dos imóveis. Desta maneira, uma parte das

\footnotetext{
3 Informação extraída do site <http://www.riomaissocial.org/territorios/vila-kennedy-em-ocupacao>. Acesso em 11 de outubro de 2015.
} 
classes de menor renda tiveram à sua disposição recursos financeiros para o financiamento da aquisição da casa própria (BONATES, 2009).

É importante destacar que, independente do objetivo de dominação social, o BNH proporcionou tanto impactos positivos quanto negativos nas cidades brasileiras, ainda que não se confirmasse como uma política habitacional justa. Positivamente, com a criação do Banco preencheu-se um vazio institucional até então não existente no campo específico da habitação social brasileira. Como aspecto negativo pode-se citar o fato do SFH, do SBPE e FGTS, não disponibilizar uma parcela maior dos recursos à classe popular, mas à classe média e alta, bem como ao setor empresarial ligado à construção civil e aos grupos rentistas. Nesta perspectiva, o BNH estimulou a acumulação capitalista e urbana, e tratou a moradia popular não como um direito social, mas como uma mercadoria qualquer (AZEVEDO e ANDRADE, 1992).

$\mathrm{Na}$ realidade, a maior contradição do BNH estava relacionada com o fato da impossibilidade de um banco suprir de maneira eficiente as necessidades habitacionais da população de baixa renda, visto que seu objetivo social entrava em conflito com a estratégia empresarial de realizar a mais-valia por meio da venda de um produto, no caso a moradia. 0 Banco dava preferência às famílias com capacidade de pagamento "compatíveis com o custo das cadernetas de poupança e letras imobiliárias, o que impedia a aplicação dos recursos para a faixa mais pobre da população" (NEVES, 2012, p. 117).

De fato, dificilmente, um trabalhador assalariado, num período de elevada concentração de renda, poderia adquirir uma unidade habitacional no Conjunto Habitacional Praia de Guarujá, pois este era bem localizado. Certamente que a injustiça praticada pela política era bastante visível. Enquanto a parte favelada da população era removida para locais inapropriados de moradia, apenas às classes médias e altas, que possuíam os recursos financeiros necessários à compra dos imóveis comercializados pelo Banco, residiam em locais tão privilegiados quanto a praia de Guarujá (SANVITTO, 2014).

Incontestavelmente, a provisão habitacional do período BNH foi pouco efetiva para o exercício de fato do direito à cidade, principalmente dado o caráter conservador dos seus mecanismos institucionais e burocráticos. A iniciativa do governo federal, apesar de necessária para a construção da moradia popular, não direcionou a maior parte dos recursos para as classes de menor poder aquisitivo, o que provocou ampliou a má redistribuição da renda e do espaço urbano. No tocante as unidades financiadas com recursos do SFH até dezembro de 1980, somente $35 \%$ destinaram-se formalmente a população que auferia rendimentos mensais 
abaixo de cinco salários mínimos. Já as classes médias e altas foram contempladas com 65\% (AZEVEDO e ANDRADE, 1982).

De acordo com os dados dos censos apresentados por Brum (1996, p.191, no período compreendido entre 1960 e 1980, a concentração econômica foi bastante acentuada em virtude das políticas econômicas dos governos militares. Ou seja, os $80 \%$ mais pobres da população economicamente ativa brasileira sofreram perdas substanciais na participação proporcional da renda que fora produzida no país, isto é, essa participação caiu de 44,8\% para 33,7\%. Em contraposição, os 10\% mais ricos tiveram, no mesmo período, um ganho expressivo, passando de $46,7 \%$ para $50,9 \%$. Portanto, fica claro que o modelo de provisão habitacional implementado, sob a égide do Capital, durante o regime militar assumiu caráter concentrador, elitista e seletivo, de forma a ampliar o grau de desigualdade social e urbana entre os anos de 1960 e 1980.

Consequentemente, em decorrência desse aumento na desigualdade de renda, a questão habitacional e urbana se agravou. Tornou-se cada vez mais difícil para a população de baixo poder aquisitivo, a obtenção de financiamentos junto ao BNH e aos demais agentes financeiros para a aquisição da casa própria. Por outro lado, aqueles que conseguiam obter os recursos necessários ao financiamento do imóvel eram deslocados para conjuntos residenciais edificados em bairros periféricos. Assim, em vez de caminhar no sentido da justiça social e urbana, a política habitacional do BNH estabelecia limites e desafios para a efetivação do direito à cidade.

O modelo de política adotado pelos governos militares, com efeito, ampliou cada vez as distâncias sociais e territoriais entre as classes sociais no cenário nacional. As diferenças entre os bairros revelavam as diferenças de estilos de vidas e, portanto, das condições e qualidade de moradia. A gestão do Estado ditatorial, excluía "do processo histórico nacional mais da metade da população do país, mantida em situação de absoluta ou relativa marginalidade econômica, social, política, cultural e educacional" (BRUM, 1996, p. 195).

$\mathrm{O}$ BNH, além de se constituir numa política injusta, não conseguiu resolver a crise habitacional dos anos de 1960. Ao contrário, apesar da retomada do crescimento econômico, durante o período militar foi crescente o número de assentamentos precários no cenário nacional.

A favelização dá saltos gigantescos justamente no período em que a economia brasileira apresenta as mais elevadas taxas de crescimento. Alguns exemplos são bastante ilustrativos a respeito: Porto Alegre possuía cerca de 30.000 favelados em 1968 e esse número sobe para 
300.000 em 1980; o Rio de Janeiro tinha aproximadamente 450.000 favelados em 1965, passando para mais de 1.800 .000 em 1980; São Paulo, a cidade mais rica do país, em apenas oito anos, de 1972 a 1980, teve seu número de favelados aumentado de 42.000 para cerca de 1.000 .000 de pessoas. E o fenômeno se reflete praticamente em todas as cidades do país, com intensidade maior nos centros urbanos mais populosos. Em vez de caminhar no sentido de construção da nação, ampliou-se a massa de marginalizados, despossuídos e excluídos (BRUM, 1996, p. 196).

Após esse período de retomada do crescimento, nos anos de 1970, os países que concediam empréstimos ao Brasil e financiavam seu crescimento acelerado sofreram perdas em suas finanças após a nova crise econômica em curso e passaram a exigir do governo brasileiro a criação de planos econômicos anti-inflacionários, bem como o corte de gastos para equilibrar as contas públicas. O resultado da crise atingiu fortemente as COHABs. Conforme os dados do Departamento de Planejamento e Coordenação (Deplan) - Rio de Janeiro apresentados por AZEVEDO e ANDRADE (1982, p. 72): “o período 1970-1974 caracteriza-se pela perda de dinamismo das Companhias Habitacionais. Financiam-se apenas 76.746 unidades, o que representa menos da metade da etapa anterior". As COHABs, por outro lado, foram prejudicadas com o desvio dos recursos produtivos para a especulação financeira.

De fato, do final da década de 1970 para cá, o capital financeiro não só dominou o mundo capitalista, como superou os investimentos produtivos no que se refere à capacidade de apropriação de lucros. Este tipo de capital procurou na especulação, a solução para a sua baixa rentabilidade, isto é, procurou no âmbito especulativo evitar a tendência à queda da taxa de lucro do sistema.

Entendemos por capital financeiro, a fusão do capital bancário com o capital industrial. À medida que se ampliava, durante o século XX, o capital a disposição dos bancos, o capital bancário passa a se constituir na principal alavanca do processo de acumulação de capitais e os bancos por meio de suas operações bancárias passam a influir decisivamente no curso da indústria (HILFERDING, 1985).

A redução dos investimentos produtivos em detrimento do aumento especulativo da capital financeiro, elevou o nível de desemprego e das perdas salariais na década de 1980. Consequentemente, o BNH já não conseguia conciliar o objetivo social da política de habitação com o modelo empresarial que norteava os seus negócios: "à medida que ganha vulto e se alastra o problema da inadimplência, as Companhias Habitacionais, se tornam vulneráveis financeiramente, desfazendo-se o sonho inicial de construir moradias para famílias de menor poder aquisitivo" (AZEVEDO e ANDRADE, 1982, p. 71). 
Esgotado o modelo de desenvolvimento capitalista centrado na industrialização por substituição de importações, implantado após a Grande Depressão, esgotaram-se também as fontes de recursos (voluntários e compulsórios) que sustentaram a política do BNH durante seus 22 anos de existência. A retração dos recursos públicos para financiar as atividades empresariais do banco aliado à crescente inadimplência dos mutuários foram fatores determinantes para o fechamento do banco no ano de 1986. Este acontecimento encerrou uma etapa importante da política habitacional no país, cujo efeito imediato foi um forte arrefecimento na oferta de habitação de interesse social.

Constatada a incapacidade do Estado brasileiro de continuar financiando o crescimento econômico e formular políticas habitacionais em acordo com os critérios de moradia adequada, ampliou-se a injustiça na distribuição do espaço urbano brasileiro. Proliferam-se loteamentos irregulares e clandestinos nas periferias, excluídos de regularização fundiária e da oferta de serviços públicos, convivendo ao lado de grandes condomínios fechados marcados pela 'segurança' de grandes muros e sistemas de câmeras de alta tecnologia

Para Valença (2001), a política econômica recessiva dos anos de 1980 contribuiu de forma decisiva para a retração dos recursos que davam suporte ao formato operacional do BNH. Com a estagnação da caderneta de poupança, do FGTS e do retorno dos financiamentos até então concedidos (prestações da casa própria), o banco faliu e o problema habitacional se agravou.

O SFH não estava preparado para enfrentar a crise, devido ao seu formato operacional. O sistema dependia do desempenho da economia, em particular dos níveis dos salários e emprego, enfim, da renda. A política recessiva impôs restrições à renda, afetando as principais fontes de financiamento do SFH: a caderneta de poupança, o Fundo de Garantia por Tempo de Serviço ${ }^{4}$ (FGTS) e o "retorno" dos financiamentos até então concedidos (prestações da casa própria) (VALENÇA, 2001, p. 29).

Enfim, a política de habitação adotada pelo $\mathrm{BNH}$, realizada num processo histórico contraditório, marcado por elevada concentração da riqueza e da renda, não tinha em seu arcabouço os elementos necessários à construção de cidades justas. Pelo contrário, a moradia passou a fazer parte dos circuitos de circulação do capital. Sem os subsídios e os investimentos públicos na área habitacional, a classe que detinha a menor parte da renda nacional se rendeu ao improviso e ocupou áreas irregulares desprovidas de coletas de lixo, coletas de esgoto, distribuição de água, patrulha e policiamento.

Em virtude da elevada densidade populacional destes espaços, a população de baixa renda foi destituída dos requisitos básicos para o desenvolvimento da cidadania plena. 
Excluídos do marco regulatório e dos sistemas financeiros formais, os assentamentos irregulares se multiplicaram em terrenos frágeis ou em áreas não passíveis de urbanização, como encostas íngremes e áreas inundáveis, além de constituir vastas franjas de expansão periférica sobre zonas rurais, eternamente desprovidas das infraestruturas, equipamentos e serviços que caracterizam a urbanidade (ROLNIK, 2006, P. 8).

O BNH promoveu a provisão habitacional em massa, mas não construiu espaços urbanos voltados para relações sociais saudáveis. As ações desenvolvidas pelo banco construíram vazios e/ou um periurbano com espaços controlados e isolados da cidade e das possibilidades de diversidade da vida urbana (NEGRELOS, 2010).

\section{CONSIDERAÇÕES FINAIS}

Registramos no decorrer desse trabalho que, conforme a visão marxista, o capitalista só se aventura no processo produtivo porque ele vê a possibilidade de realizar a mais-valia gerada pela força de trabalho. O empresário ou o bancário não estão preocupados em produzir valores de usos, no caso a moradia, mas em promover o processo de acumulação urbana. Portanto, quando a produção, seja ela qual for, não consegue encontrar mercado, acaba por sofrer uma crise, a qual Luxemburgo denominou de crise de subconsumo. Tais crises ocorrem porque o modo de produção capitalista tende a produzir um valor muito maior do que consegue realizar (vender no mercado). Contudo, o capitalismo tem muitas maneiras de contrabalancear as crises econômicas. Aqui destacamos a cooptação da produção habitacional produzida no âmbito do BNH, na década de 1960.

O fato é que o elevado nível de investimento estatal injetado no processo de urbanização, no pós-guerra, tanto nos países desenvolvidos como nos países de terceiro mundo, dinamizou os setores produtivos, inclusive da construção civil, em detrimento da produção da boa moradia para os trabalhadores urbanos. A inserção dos recursos públicos tornava-se necessária, nos grandes centros urbanos porque a iniciativa privada não tinha meios de realizar tal produção apenas pelas forças livres de mercado, ou seja, pela iniciativa privada.

Se o investimento público demanda insumos como construção civil e máquinas e equipamentos, e ainda, se as políticas públicas de subsídios e crédito beneficiam a produção doméstica, desloca-se a estrutura produtiva para setores mais intensivos em capital e tecnologia. A indústria capital-intensiva, por seus efeitos de encadeamento, eleva a produtividade e dinamiza a economia. Se os ganhos de produtividade forem acompanhados de elevação dos salários reais, constitui-se, assim, a marcha ao desenvolvimento (REIS, 2008, p. 14). 
Nesse processo, o modelo do SFH consistiu numa solução capitalista para a construção das habitações, tendo por objetivo principal, não apenas a produção da moradia social como um direito, mas como uma mercadoria. Outro motivo importante para a atuação do BNH foi a tentativa de desestabilizar os movimentos reivindicatórios da classe trabalhadora contra o regime militar. O fato é que, naquele período de elevada instabilidade social, ser proprietário do seu próprio "chão" significava a segurança a proteção contra o processo recessivo e os conflitos políticos. Logo, a dominação da classe trabalhadora sob a ideologia da casa própria, acabou por ampliar as desigualdades sociais, econômicas e urbanas, beneficiando de forma direta o empresariado da construção civil, as classes médias e altas em detrimento do segmento popular.

Assim, concluímos que a política de habitação promovida pelo Estado, pelo capital produtivo e mercantil durante o período de 1964 a 1986, revelou a existência contraditória do fenômeno urbano: Locus de valorização do capital e mercadoria - tencionada por diversos agentes sociais - cuja propriedade tem assegurado a apropriação de rendas extraordinárias.

Embora a análise aqui estabelecida tenha incidido sobre a produção da moradia sob a liderança de um banco, ou seja, do BNH, o fenômeno da cooptação da provisão habitacional ocorre em qualquer política de habitação formulada nos moldes do financiamento público ou privado e que tenha por meta principal a realização da mais-valia. É uma política que se guia na direção da (des) construção do direito à cidade, já que exclui a classe de menor renda das áreas centrais, equipadas com todos serviços públicos e infraestrutura adequada. Longe destas áreas, ficará muito difícil para a população de baixa renda se inserir nos mercados de trabalho e, portanto, desenvolver a sua plena cidadania.

\section{REFERÊNCIAS BIBLIOGRÁFICAS}

AZEVEDO, S.; ANDRADE, L. A. G. de. Habitação e poder - Da Fundação da Casa Popular ao Banco Nacional da Habitação. Rio de Janeiro: Zahar, 1982.

BLAY, E. Eu não tenho onde morar: vilas operárias na cidade de São Paulo. São Paulo. Nobel, 1985.

BONATES, M. F., Ideologia da casa própria... sem a casa própria: O Programa de Arrendamento Residencial na Cidade de João Pessoa - PB., João Pessoa, Ed. Universitária da UFPB, 2009.

BRUM, J. A. O Desenvolvimento Econômico Brasileiro. Petrópolis: Vozes, 1996. 
CANO, W. Reflexões sobre o papel do capital mercantil na questão regional e urbana do Brasil. Texto para Discussão. IE/UNICAMP n. 177, maio 2010.

CARCANHOLO, M. D. Apontamentos críticos sobre a teoria da crise em Rosa Luxemburgo, 1987. em:<http://www.unicamp.br/cemarx/anais_v_coloquio_arquivos/arquivos/comunicacoes/gt1/s essao1/Marcelo_Carcanholo.pdf. Acesso em: 07 jan 2017.

FAGNANI, E. Política Social no Brasil (1964-2002): Entre a Cidadania e a Caridade. Tese de Doutorado - Universidade Estadual de Campinas - UNICAMP - Instituto de Economia - IE, Campinas, 2005.

HARVEY, D. A Produção Capitalista do Espaço. São Paulo: Annablume, 2005

The enigma of capital and the crises of capitalismo. 2. ed. London: Profile Books, 2011. Edição brasileira: O Enigma do Capital. . São Paulo: Boitempo, 2011.

The right to the city. International Journal of Urban and Regional Research. Vol. 27, issue 24. December, 2003. Disponível em:< http://onlinelibrary.wiley.com/doi/10.1111/j.03091317.2003.00492.x/abstract. > Acesso em: 07 jul 2015.

HILFERDING, R. O Capital Financeiro. São Paulo: Nova Cultural, 1985.

LEFEBVRE, H. O direito à cidade. São Paulo: Centauro, 2001.

LÊNIN, V.I., A Luta de Classes, In: Obras Escolhidas em três tomos, Edições Avante! - Edições Progresso, Lisboa-Moscovo, 1977, t. 1, p. 13.

LOJKINE, J. O Estado capitalista e a questão urbana. São Paulo: Martins Fontes, 1981.

LUXEMBURG. R. A Acumulação do Capital. São Paulo: Nova Cultural, 1985.

MARICATO, E. Metrópole na periferia do capitalismo: ilegalidade, desigualdade e violência. São. Paulo: Hucitec, 1996.

MARX, K. O Capital: crítica da economia política, Livro 3/Volume V - O Processo Global de Produção do Capitalista. São Paulo: Ed. Difel, 1985.

MARX, K. O Capital, Crítica da Economia Política. São Paulo: Nova cultual 1988.

OLIVEIRA, Fabiana Luci de. STF: do autoritarismo a democracia. Rio de Janeiro: Elsevier, 2012.

NEGRELOS, E. P. Habitação Social no Brasil pós-1964. Arquitetura, Cidade e Gestão. Um estudo comparado entre a produção do BNH/COHABs e da CEF/PAR em cidades do Estado de São Paulo. Primeiros resultados em São Paulo e São Carlos. ANAIS DO I ENAMPARQ. Rio de Janeiro, 2010. Disponível em: <http://www.anparq.org.br/dvd-enanparq/simposios/67/67-276-1-SP.pdf>. Acesso em: 22 jul 2014.

NEVES, R. T. C. A política de crédito imobiliário na efetivação do direito à moradia: um ensaio da aplicação da análise jurídica da política econômica. Dissertação de Mestrado apresentada à faculdade de Direito da Universidade de Brasília. Brasília: UNB, 2012. 
RJTV. Disponível em <http://g1.globo.com/rio-de-janeiro/rio-450-anos/noticia/2015/03/foinoticia-em-1965-governo-removia-moradores-de-favelas-do-rio.html>. Acesso em: 07 out 2015.

ROLNIK, R. Para além da lei: legislação urbanística e cidadania (São Paulo 1886-1936). SOUZA, Maria Adélia A.; LINS, Sônia C.; SANTOS, Maria do Pilar C.; SANTOS, Murilo da C. (Org.). Metrópole e Globalização-Conhecendo a cidade de São Paulo. São Paulo: CEDESP, 1996.

REIS, C. F. B. Os Efeitos do Investimento Público sobre o Desenvolvimento Econômico: análise aplicada para a economia brasileira entre 1950 e 2006. Tesouro/Fazenda, 2008. Disponível em: <file:///D:/A\%20-\%20TEMAS/A\%20-\%20Keynes/tese\%20premiada\%20gasto\%20publico.pdf>. Acesso em: 24 set 2014 .

RUBIN, I. I. A Teoria Marxista do Valor. São Paulo, Brasiliense, 1980.

SANVITTO, M. L. A. Conjuntos habitacionais promovidos com recursos do Banco Nacional de Habitação: a falta de uma crítica arquitetônica. Anais do III ENANPARQ. Arquitetura, cidade e projeto: uma construção coletiva. São Paulo, 2014.

TRINDADE, T. A. Direitos e Cidadania: reflexões sobre o direito à cidade. Lua Nova, São Paulo, 87, p. 139-165, 2012.

TROMPOWSKY, M. A FCP - Fundação da casa popular e a implantação de uma política habitacional no Brasil: o processo de uma experiência governamental no campo da habitação popular. Disponível em: Rbeur, n. 4, v.8, 2004. Disponível em: <http://www.anpur.org.br/revista/rbeur/index.php/shcu/article/view/1050>. Acesso em: 07 fev 2014.

VALENÇA, M. M. Globabitação. Sistemas habitacionais no Brasil, Grã-Bretanha e Portugal. São Paulo: Terceira Margem, 2001.

Trabalho enviado em 28 de fevereiro de 2017.

Aceito em 02 de abril de 2017. 